\title{
International and Domestic influences on Green Energy Policy in India
}

\author{
${ }^{1}$ Akshara Baru, ${ }^{2}$ Dr.Usha Ramachandra \\ ${ }^{l} 5^{\text {th }}$ year student, BBA LLB; Symbiosis Law School, Pune. \\ ${ }^{2}$ Prof. and Chairman, Energy Department, Administrative Staff College of India
}

\begin{abstract}
This paper aims to understand formulation of green energy policy in India and the various attributes that influence such policy formulation. Energy has become a driving force for much development and with time there has been a growing concern on both the importance as well as the relevance of using environmental friendly energy in developing countries. Hence, this paper discusses the insidious concern of climate change and the increased international pressure on the need to change to newer, less polluting forms of energy. The paper emphasizes on aspects which determine energy policy conception which include development, poverty, domestic conditions, and feasibility of implementation which are not isolated in this process. The paper further analyses that in spite of the increased international burden for exclusive climate sensitive policies, Indian green energy policies still reflect domestic concerns. Hence, India adheres to the aforementioned domestic concerns during policy constitution, thus forming a locally relevant and globally participatory policy.
\end{abstract}

\section{Introduction}

Climate change is advancing rapidly. Without a fool proof counter mechanism in place, a temperature increase of $2-7{ }^{\circ} \mathrm{C}$ relative to the pre-industrial levels is expected to occur by the end of this century. The former UN General Secretary Kofi Annan, in his opening address in the Conference of Parties to the UNFCCC, ${ }^{1}$ described climate change as a potential threat to the peace and security of the world.

The Intergovernmental Panel on Climate Change (IPCC) predicts that the effects of climate change will vary from region to region and their intensity will increase with time. The IPCC has further forecasted the potential threats that each continent will have to experience if no resolute counteraction channel is in place. A 520 percent rise in rain-fed agriculture, reduction in level of snow in western mountains and increase in the intensity of the heat waves in certain cities are some of the perils North America will experience. Europe will have to combat frequent coastal flooding, threat of increased glacial retreat, a considerable loss in species and wildlife, fall in crop produce in the southern regions of Europe and a risk of inland floods. South America will see a considerable change in the amounts of water that will be available for human consumption as well as for energy generation. The Amazonian regions of Latin America will also experience a progressive replacement of the tropical rain forests by Savannah grasslands which will be a huge blow on the country's natural wildlife abundance. Extinction of rich species in the tropical areas is also predicted. Dearth in freshwater availability in many regions of Asia and increased susceptibility to diseases with increase in floods and droughts are indicated according to the reports of the IPCC (IPCC Synthesis report, 2007).

As climate change happens to be one of the greatest threats globally, an urgent and a sustainable solution for combating it must be put in place. The IPCC in their report (2011) emphasizes the importance of renewable energy to mitigate the insidious climate change crisis being faced by the world. The report further goes on to recognize the tremendous potential of renewable energy in meeting our energy needs as well as its significance in countering the challenge of climate change.

As climate change is a global problem, promotion of green energy has also gained significant importance in India. Keeping in view the vast dependency on coal and petroleum for both household use as well as for other purposes and also, with the increased international contemplation given to the issue of climate change, there has been sudden attention given to the nature of fuels being used. Research has shown that renewable energy sources have the potential to satisfy a fairly significant component of the country's energy needs as well as contribute significantly to energy security. In order to buttress the country's energy security, there is an urgency to scale up the use of clean energy sources. Especially in India where to keep pace with the fast growing economy about 3-4 times more energy production is required which can only be achieved by harnessing energy sources like solar energy, geothermal energy, biomass energy, ocean energy, wind energy which can help India overcome its existing and potential energy shortage without causing damage to the

${ }^{1} 12^{\text {th }}$ session of the Conference of Parties to the UNFCCC; $15^{\text {th }}$ November,2006

UNFCCC- United Nation Framework Convention on Climate Change 
environment. There has been considerable efforts and pursuit relating to research, policy and development of renewable energy mechanisms for use in various sectors (Kaushik ; Kumar A; Kumar K; Mishra; Sharma; 2010). These developments do not occur in a vacuum, but in a dynamic interplay of international and domestic political and economic obligations, this paper explores the motivations and interactions behind the policy decisions as well as their formulations.

\section{Discussion}

The UNFCCC in its articles ${ }^{2}$ defines climate change as the change of climate which is attributed either directly or indirectly to human activity which alters the composition of the global atmosphere and which is in addition to natural climate variability observed over comparable time periods.

Causes of climate changes can be categorized as either "natural" or "anthropogenic ${ }^{3 \text { " }}$ according to their sources (WMO report). But, it is to be observed here that the UNFCCC has defined climate change as a result of human activity. A survey done of more than four thousand academic papers on climate change that were published over the last 20 years observed that $97.1 \%$ agreed that one of the major cause of climate change due to the activities of human beings. Therefore climate change has been a consequence of, either absolutely or in part, human development and activity.

There is a regular discharge of greenhouse gases and other aerosols into the Earth's atmosphere which has only increased over the last century due to continuous human activity. The greatest known contributor to this increased level of green house gases emission is from the burning of fossil fuels. Fossil fuels are carbon rich fuels that have been naturally formed by the anaerobic decomposition of buried organisms over years. Burning of these naturally occurring fuels releases carbon dioxide in large quantities which in turn contributes to the process of global warming. The Earth's energy balance is disrupted as these green house gases that are emitted into the atmosphere as a product incessant of human activity which alters the incoming and outgoing solar rays. Thus this alteration in the Earth's energy system either causes warming or cooling of the earth climate system (IPCC Working Group I report).

Energy is essential for almost all economic and social activities. Most of the times, energy usage and direction is an indicator of country's development. However, as discussed during the causes of global warming, the sustainability of development depends on the impact on environment energy usage has. It should therefore be noted that over "... 85\% of current primary energy driving global economies comes from the combustion of fossil fuels and consumption of fossil fuels accounts for 56.6\% of all anthropogenic GHG emissions" (IEA report, 2010). These emissions would only heighten with continued growth, and inevitably flood higher levels of carbon into the atmosphere with time. With usage of energy inevitable for development and essential processes, this calls for a shift in our energy sources.

Renewable energy technologies that seek natural sources can address a wide range of energy needs with little or no GHG emissions (IPCC report, 2007). Added to this, the global energy demand and volatile competitiveness pushes for greener energy technologies as less socially and environmentally burdensome. As of 2008 , green energy technologies "account for $12.9 \%$ of the total $492 \mathrm{EJ}^{4}$ of primary energy supply"(IEA report, 2010). A majority of these contributions accounted for biomass, solar and geothermal energy supply for global electricity and fuel supply. Clearly, the share of global green energy supply is less than desired and varied across countries. Collectively, "..... developing countries hosted 53\% of global RE power generation capacity in 2009" (Demirbas, 2009). These developments point to the role of policies in stimulating transitions and push towards renewable technologies. It has been shown that policies, mixed with market favorability towards greener energy provide the synergy for successful innovation and expansion of these technologies. Other factors included infrastructure, public awareness, institutional norms, trade regulations, laws and financial incentives (Moomaw, Yamba, Kamimoto, Maurice, Nyboer, Urama, Weir; 2011).

\section{Green Energy And India}

Experts believe that the approach adopted by India for the international climate change negotiations is a traditional one. Sticking to basic principles of equitable burden sharing India has not taken up concrete obligations to for reduction of GHG emissions. Being a developing nation, India has shifted the responsibility of reduction on developed nations. The Indian Renewable Energy Status Report (DIREC) 2010 states that the current rate of emission of green house gases is 4 percent of the global emissions. The per capita emission is even less accounting to only one quarter of the overall average of nations worldwide. Hence, apart from having

\footnotetext{
${ }^{2}$ UNFCCC Article 1 Sub clause 2

${ }^{3}$ Human induced causes

${ }^{4}$ EJ- Exajoule

The SI derived unit for energy is the joule.

1 joule is equal to $1.0 \mathrm{E}-18 \mathrm{EJ}$.
} 
relatively low rates of emission as compared to other countries, such an approach can be attributed to a few other factors as well.

Poverty being rampant in India, there is a clear limitation on the material resources available. A limitation on financial and technical capacities followed by the notion that overall development of the nation would be compromised if global agendas of prioritizing environment issues would be in place have been hindrances preventing India from taking an assertive policy decision on a global scale. A Government of India, 2006 report states that five hundred million citizens of India still do not have access to electricity or other resources hence; there is general dilemma to redirect available materials away from basic necessities.

There is also, to a certain degree, a lack of trust in international agendas and decisions. India continues to adhere to conventional methods of policy for combating climate change. This approach can be attributed to the ineffectiveness in the implementation of the Kyoto Protocol, the notion that developed countries are using climate change to reduce the rate of development of countries like India and China and the concern that international policies would overlook "equity" thus delivering poor outcomes to such developing countries.

It can be said that the approach India has taken on climate policy is to some degree different from that of the other foreign policies of the country. A sense of sovereignty and need to conserve national integrity and not have its domestic priorities over looked in the vast landscape of the international agendas can also be one of the reasons for certain loopholes existing in formulation of exclusive climate change combating policies (Atteridge, Pahuja, Shrivastava, Upadhyay, 2012).

Even with the differences mentioned, India still continues to be a fierce participant and is emerging as one of the most important players in the negotiations between countries at the international level. The repercussion of this active participation can be seen in the national and sub national policies in place. But to understand the implications of such policies and their nature it becomes essential to peel them and understand the reasons for such policy formulation and their effectiveness in the long run for the development of the country and in combating climate change and also the contribution of international parties in such domestic policies.

With understanding the policies in place in India one can also understand the reasons for such policies and the key drivers that influence the formulation of policies of such nature. There can be a distinction in the nature of policies at the international level, where policy formulated is to cater to foreign policy needs, and national level policies highlight development concerns and have other national interests interwoven in them (Atteridge, Pahuja, Shrivastava, Upadhyay, 2012).

India has over the years recognized and admitted that climate change is a global concern which needs to be looked into and tackled by the world at large. Promotion of green energy has primarily in the last few years become a priority for many nations of which India is a nation that has in order to address these issues of climate change formulated restrictive policies and binding legislations (Batel, Devine, Wright, Tangeland, 2013).

By observing the evolution of Indian policies relating to environment it can be said that a major part of it has been influenced by international agendas and agreements. For instance, the Environment Protection Act 1986 and the Air (Prevention and Control of Pollution) Act 1981 clearly show connection to international processes. The implementation of the National Environment Tribunal Act, 1995 also happens to India's pro active response to the Rio Summit. Even the objectives of sector specific policies like the National Environment Policy 2006 (NEP) $)^{5}$ have international principles encapsulated in them thus proving the impact of International intentions over India (Atteridge, Pahuja, Shrivastava, Upadhyay, 2012). But such an influence of international agreements and their long term targets must also be kept in check as their dominance leads to the common contention that such climate policies hinder economic growth. Primarily, the developing nations which do not have the resources to replace already existing technology with improved environmental friendly technology (Guivarch, Mathy, 2010). The contributions of our former Prime Minister Mrs.Indira Gandhi also show the tensions that prevail between environmental policy and goals of development.

Even today, a large portion of the country's population, due to its varied socio economic dimensions, still resides in the rural areas and largely depends upon climate sensitive factors which include forestry, farming, fishery etc for their livelihood. Even with its recent rapid growth rate and advanced technologies in information, nuclear, wind and solar power fields a large part of India still continues to have no access to electricity.

\footnotetext{
${ }^{5}$ The Preamble of the National Environmental Policy, 2006 recognizes the interdependencies among, and transboundary character of, several environmental problems', and the present policy is 'a statement of India's commitment to making positive contribution to international efforts.

The Policy further specifically recommends that new legislation should be enacted in line with multilateral environmental regimes, and various norms embedded in international agreements. These include notions of environmental standards, social responsibility and the offsetting of environmental impact through mechanisms promoting economic efficiency.
} 
With conditions of dire poverty, having almost $45 \%$ of its children in still remaining malnourished, shortage in goods and services emerging rapidly and a vast section of the society still constituted of the middle class the national policies drawn to combat climate change continue to be influenced by the prerogative to diminish poverty simultaneously with the goal to enhance sustainable development. Though it can be said that there is considerable international influence over the country in the realm of ideas and ambitions, the domestic concerns as well as policies of the nation still bend towards fundamental needs and material requirements of the citizens (Atteridge, Pahuja, Shrivastava, Upadhyay, 2012). Therefore the country affirms to the principles of equity thus affirming that global issues such as climate change should be addressed adhering to the concept of "common but differentiated responsibility" ${ }^{6}$ " and the "historical responsibility" perspective. India continues to stick to the argument that every agreement so made should be keeping in mind the global goal of converging per capita emissions thus reiterating that each individual has the same right to the atmosphere.

Developing countries faced criticism post the UNFCCC when it was binding for the developed countries to admit to the reduction in the emission of green house gases. Developed countries such as the United States which agreed to take legally binding steps for decrease in emission, faced domestic opposition. Most of these countries argued that rapidly developing nations such as India and China would soon become major green house gas emission centers thus contributing largely to climate change ${ }^{7}$. Further confrontation between the developed and developing countries emerged with poor progress in the implementation of the Kyoto Protocol followed by sudden awareness globally about consequences of climate change ${ }^{8}$ leading to increased pressure on developing countries to accede to the binding commitments. With China ${ }^{9}$ turning pro active to issues of climate change and advanced policies there was augmented pressure on India to accept these international agreements.

The Energy Conservation Act (2001) was one such initiative by the Indian Government. It was developed as a strategy to make power available to most citizens by the year 2012. The Act emphasized on the provision of a legal arrangement with institutional framework and regulatory mechanisms both at the Central and State level to promote energy efficiency and narrow the gap between demand and supply. But, the targets so set by the Act could not be met.

But despite the above mentioned policy in place and the internationally growing pressure on India from the beginning of the century, only in the last few years did India see substantial change in policy and greater awareness about the issue of climate change. The impacts such as the irregular monsoons, the altered Himalayan glacier system, the threat to the water security and increase in the sea level lead to India understanding its vulnerable place and the government establishing a national Council on Climate Change. This Council that included government officials and experts in the field of environment formulated the National Action Plan for Climate Change (Chakravarty, Ramana, 2009). Though it may be said that the initiation of the NAPCC was initially India's response to the international advancements in highlighting climate change yet, the eight missions that the Plan contains mainly address the national issues of poverty and development ${ }^{10}$. The NAPCC clearly holds the idea that most policies that are related to mitigation of climate change are influenced by material concerns of a developing nation such as keeping a considerable check on its diminishing resources, to sustain a high macro-economic growth addressing the problems of depleting sources of energy (Atteridge, Pahuja, Shrivastava, Upadhyay, 2012).

The eight missions under the National Action Plan on Climate Change are as follows. The Government of India Ministry of New and Renewable Energy (report 2012) describes the Jawaharlal Nehru National Solar Mission (JNNSM) as a mission that encourages utilizing of the abundantly available solar energy thus enhancing recourse efficiency and building energy security of the country. This mission having being launched in the year 2010 by the government aims at decentralizing energy supply technology and thus empowering the rural poor of India through a consistent and a well planned long term policy, improved and more aggressive R \&

\footnotetext{
${ }^{6}$ Common but differentiated responsibility; The Rio Declaration: "In view of the different contributions to global environmental degradation, States have common but differentiated responsibilities. The developed countries acknowledge the responsibility that they bear in the international pursuit of sustainable development in view of the pressures their societies place on the global environment and of the technologies and financial resources they command." Similar language exists in the Framework Convention on Climate Change; parties should act to protect the climate system "on the basis of equality and in accordance with their common but differentiated responsibilities and respective capabilities." The principle of common but differentiated responsibility includes two fundamental elements. The first concerns the common responsibility of States for the protection of the environment, or parts of it, at the national, regional and global levels. The second concerns the need to take into account the different circumstances, particularly each State's contribution to the evolution of a particular problem and its ability to prevent, reduce and control the threat.

${ }^{7}$ March 200 President George W. Bush's letter to the U.S. Senate

${ }^{8}$ Awareness among people of the effects of climate change, including the loss of glaciers and Arctic sea ice, prolonged dry spells and heat waves, disastrous events like Hurricane Katrina, and the risk of catastrophic change like the loss of Greenland's ice-sheet.

${ }^{9}$ This switch should be seen in light of the considerable difference between these countries. India's per capita emissions are a third of China's today. According to most projections, in 2030, they are likely to remain lower than China's today, both in absolute and per capita terms. This is one reason that China is expected to, and is willing, to make stronger commitments in the future.

${ }^{10}$ The NAPCC states that India's policy response to climate change will primarily address 'the urgent and critical concerns of the country' with 'co-benefits for addressing climate change' through 'a directional shift in the development pathway', thereby assigning priority to the maintenance of high economic growth.
} 
D sector, formulating large scale deployment goals and production of raw materials and components thus attempting at deploying the ambitious target of producing 20,000 MW of grid connected solar power by 2022 .

The energy efficiency of India is rated as the fifth lowest in world. There is high scope for improvement of energy efficiency in the country but such transition of reducing usage of fossil fuels without affecting the growth rate of the country is required (Center for Development Finance report). Also, with the increased concern about depleting energy resources globally there is an increased energy security threat to countries over all. The second mission of the NAPCC aims at increasing corporate acceptability of cost effective energy methods through market mechanisms. The National Plan on Enhanced Energy Efficiency (NPEEE) aims at using improved managerial innovation and technology for increasing energy efficiency by upgrading existing technology and implementing certain global efficiency standards (Chakravarty, Ramana, 2009).

The National Mission on Sustainable Habitat (NMSH) passed in the year 2010 by the Prime Minister's Council for Climate Change emphasizes on the optimization of energy demand. This can be achieved through having a climate threat and a disaster resilient infrastructure in place through a system of better urban planning. One of the most prominent deliverables if the mission is the inclusion of National Sustainable Habitat Standards which would over time be amalgamated with relevant regulations thus ensuring that development in future is in sync with climate change concerns (Ministry of Urban Development report, 2011).

Water management and waste minimization in water bodies are integrated in the National Water Conservation Mission. The mission recognizes five goals to achieve its objective ${ }^{11}$. The goals of the National Water Mission include promotion of state action in water management, increased citizen participation in water management, highlighting attention to vulnerable areas and over exploited regions, formulation of a comprehensive and detailed water data base which includes an assessment of climate change impacts on water resources in the public domain, promotion of water use efficiency by at least $20 \%$ and an upgraded water resource management in place (Ministry of Water Resource report, 2011).

The National Mission on Sustainable Agriculture (NMSA) aims at transforming agriculture into a production system that is climate resilient. Food security concerns and economic instability in rural livelihoods have made sustainable agriculture important. A large portion of the population of India is dependent on agriculture which is climate-vulnerable hence ensuring food security and uniform access of food to all, enhancing opportunities to all and producing ecologically sustainable agriculture is essential (Department of Agriculture and Cooperation; Ministry of Agriculture, Govt. of India, 2010).

For maintain ecologically balance and protecting livelihood and biodiversity the Green India Mission (GIM) recognizes that the issue of climate change should be seriously addressed. The Ministry of Environment and Forests in their report (2011) recognizes that the quality of natural resources available in the country and their distribution would be seriously affected by climate change. The report further recognizes the impact on environment that the forest sector has hence for preserving the communities that are dependent on forests, preserving ecological balance and conserving biodiversity through an efficient system of forest management should be adopted. Forest further act as carbon sinks ${ }^{12}$. Judicious usage of land is also of essential nature.

Protection of the Himalayan Ecosystem is very important as the Himalayan glaciers form the source for a number of fresh water reserves that further go on to providing water for major rivers of the world (Department of Science \& Technology, Government of India) hence, the National Mission for Sustaining the Himalayan Ecosystem (NMSHE) emphasizes on the conservation of perennial rivers and the rich biodiversity reserves on the Himalayas.

The eighth mission passed by the government emphasized on promoting collaboration and unity at the international level. The National Mission on Strategic Knowledge on Climate Change recognizes the need to have newer and improved scientific technology by establishing research centers and raising the national standards by improving international relations thus sharing cleaner and more efficient technology.

\section{Conclusion}

The paper begins by establishing through review of diverse literature from climate science journals and energy analysis papers that there is an urgent need to shift from current models of hydro-carbon based energy creation to greener and renewable options. There is little doubt that the role of policy of countries is tantamount towards this shift, in the context of a rapidly racing competition among economies in using energy dependent growth. The paper has also sought to show the role of politics, power and political economy to establish a renewable energy system. It has been seen that the effects of such a system would impact the mitigation of an

\footnotetext{
${ }^{11}$ The objective of National Water Mission is "conservation of water, minimizing wastage and ensuring its equitable distribution both across and within States through integrated water resources development and management" (Ministry of Water Resources report, 2011)

${ }^{12}$ A carbon sink is a natural or artificial reservoir that accumulates and stores some carbon-containing chemical compound for an indefinite period. Forests are carbon stores, and they are carbon dioxide sinks when they are increasing in density or area for example in Canada's boreal forests as much as $80 \%$ of the total carbon is stored in the soils as dead organic matter (Canadian Forest Service Science; Policy Notes; Natural Resources Canada; 2007)
} 
impending climate catastrophe, but goes the long way of enhancing employment opportunities, consolidating energy security amidst rising oil prices and volatility and thus, boosting economic growth. The above factors have generally informed the internal discourse in its laws and regulations; India has unique additional factors of bio-diversity owing to its ecological diversity, and more importantly, the issue sustainable development owing to the dependence of a considerably large population's dependency on forests and other ecology. India's political discourse in combating climate change through renewable energy policy emerged through its seemingly contradictory positions - first being its disillusionment with the international agenda because of its commitment to growth, and secondly the need address issues such as insecurity in the forest dependant low-income groups and sustaining its bio-diversity. As an outcome, this local agenda of preservation, sustainability and development pushed India as key player in the international arena of climate change reduction through its enrollment into important protocols, conventions and groups. The paper concludes to show that the outcome of local drive for conservation, despite initial lack of clarity in international climate participation, saw India emerge as leading key player in climate change reduction through its local programs and even through enrolments in important protocols, conventions and groups. However, the weight of discourse tilts towards local agenda, expressing through social and development benefits while levering additional sources of clean energy. In so doing it has gone beyond a narrower set of diplomacy factors. The recent embarking on a rapid paced development of 74,000 MW of additional renewable resources over the next decade, including 20,000 MW of solar power and somewhere between 40,000 and 50,000 MW of wind in its policy decisions establishes this journey.

\section{References}

[1]. Intergovernmental Panel On Climate Change; (2007); The Physical Science Basis; Contribution Of Working Group I To The Fourth Assessment Report.

[2]. Ashwani Kumar, Kapil Kumar, Naresh Kaushik, Satyawati Sharma, Saroj Mishra; (2010); Renewable Energy In India: Current Status And Future Potentials; Elsevier; Renewable And Sustainable Energy Reviews 14 (2010); 2434-2442

[3]. World Meterological Organisation; Causes Of Climate Change[Online]; (Viewed 10 June 2013); Available FromHttp://Www.Wmo.Int/Pages/Themes/Climate/Causes_Of_Climate_Change.Php

[4]. International Energy Agency; (2010); World Energy Outlook; Edition 2010.

[5]. Mohar Chattopadhyay, Deb Chattopadhyay; (2012); Analysis Of Indian Renewable Energy Policy Using Climate Data; Elsevier; Vol. 25, Issue 3 1040-6190.

[6]. Moomaw, F. Yamba, M. Kamimoto, L. Maurice, J. Nuboer, K. Urma, T. Weir; (2011); Introduction. In Ipcc Special Report On Renewable Energy Sources And Climate Change Mitigation; [O. Edenhofer, R. Pichs-Madruga, Y. Sokona, K. Seyboth, P. Matschoss, S. Kadner, T. Zwickel, P. Eickemeier, G. Hansen, S. Schlömer, C.Von Stechow (Eds)], Cambridge University Press, Cambridge, United Kingdom And New York, Ny, Usa.

[7]. Sandrine Mathy, Ce'line Guivarch; (2010); Climate Policies In A Second-Best World- A Case Study On India; Elsevier; Energy Policy 38 (2010) 1519-1528.

[8]. Prime Minister's Council On Climate Change; (2008); National Action Plan On Climate Change; Government Of India.

[9]. Atteridge, Shrivastava, N. Pahuja, H. Upadhyay; (2012); Climate Policy In India: What Shapes International, National And State Policy; Pubmed; 41 Suppl 1:68-77.

[10]. Shoibal Chakravarthy, M.V.Ramana; (2009); India's Evolving Climate Change Strategy; Climate Science And Policy.

[11]. Susana Batel, Patrick Devine Wright, Torvald Tangeland; (2013); Social Acceptance Of Low Carbon Energy And Associated Infrastructures: A Critical Discussion; Elsevier; Energy Policy Volume 58, Pages 1-5.

[12]. Ministry Of Water Resources; (2011); National Water Mission; National Action Plan On Climate Change; Comprehensive Mission Document, Vol-I; Government Of India.

[13]. Ministry Of Urban Devlopment; (2011); National Mission On Sustainable Habitat; National Action Plan On Climate Change; Government Of India.

[14]. Ministry Of Agriculture; (2010); National Mission On Sustainable Agriculture; National Action Plan On Climate Change; Government Of India. 